\title{
Characterization and removal of natural organic matter from slow sand filter effluent followed by alum coagulation
}

\author{
Euis Nurul Hidayah ${ }^{1} \cdot$ Yung-Chen $\mathrm{Chou}^{2} \cdot$ Hsuan-Hsien $\mathrm{Yeh}^{2}$
}

Received: 13 August 2017 / Accepted: 11 January 2018 / Published online: 22 January 2018

(C) The Author(s) 2018. This article is an open access publication

\begin{abstract}
Characterization and removal of natural organic matter, which is contained in the effluent of slowsand filters, was observed by alum coagulation under various dosages. In addition to non-purgedable dissolved organic carbon (NPDOC), trihalomethanes formation potential (THMFP) and haloacetic acid formation potential (HAAFP) measurement, high-performance sizeexclusion chromatography (HPSEC) with ultraviolet/visible and dissolved organic carbon (DOC) detectors was used to characterize the various organic fractions contained in the water before and after coagulation. The results show that alum coagulation could effectively remove hydrophobic aromatic, which forms mainly humic substances. The reduction in THMFP was found to be higher than that of NPDOC and HAAFP under specific alum dosage, and the former was also found to be proportional to the corresponding reduction in the area of hydrophobic aromatic fraction, mostly humic subtances, as obtained from HPSEC chromatogram with peak-fitting.
\end{abstract}

Keywords Coagulation $\cdot$ HPSEC $\cdot$ Peak-fitting

\section{Introduction}

Natural organic matter (NOM) is a complex mixture of heterogeneous organic matter present in natural waters. NOM affects the performance of the unit processes of water treatment, in addition to the biological stability in drinking water. The amount, character, and properties of NOM differ in waters and depend on the biogeochemical cycles of the surrounding environments. Disinfection by-products (DBPs), of which trihalomethanes (THMs) and haloacetic acids (HAAs) are the major groups, were formed when NOM reacts with a disinfectant such as chlorine. The varying leves of DBPs formation are dependent upon the reactivity of the NOM, chlorine dose, $\mathrm{pH}$, temperature, reaction time, and bromide concentration (Roccaro et al. 2008; Han et al. 2015). Therefore, the removal of dissolved organic in drinking water treatment is important for controlling disinfection by-products (DBPs)

Euis Nurul Hidayah

euisnh@gmail.com

1 Department of Environmental Engineering, University of Pembangunan National "Veteran" Jawa Timur, Surabaya, Indonesia

2 Department of Environmental Engineering, National Cheng Kung University, Tainan 70101, Taiwan formation and for preventing water quality deterioration in distribution system caused by biofilm formation.

Several treatment options have been studied for NOM removal from source water. Generally, coagulation is considered as the most common and feasible process for NOM removal. The removal of NOM by coagulation using inorganic coagulant is influenced by the character of NOM and factors such as $\mathrm{pH}$ and alkalinity of source water. NOM can be characterized in terms of its humic and non-humic fractions, its hydrophobic and hydrophilic properties, and the molecular weights of its constituents (Tran et al. 2015; Hidayah et al. 2016). Humic fractions, which generally have higher aromatic content, higher charge, and more hydrophobic tend to be more easily removed by coagulation through charge neutralization mechanism (Aslam et al. 2013; Hidayah et al. 2017). In charge neutralization, cationic metal hydrolysis products interacts with anionic NOM to form insoluble charge-neutral products. The non-humic fractions, which consist of biopolymers, such as polysaccharides and proteins, are more hydrophilic. The possible coagulation removal mechanism of these fractions is to be adsorbed onto metal hydroxide surface or floc (Chow et al. 2009). In addition, the formation of insoluble metal hydroxide will cause entrapment of NOM or sweep coagulation. Floc formed during various coagulation mechanisms has been observed 
to have different properties of size, structure, and strength, which is influenced by coagulant type and dosage (Sharp et al. 2006; Chow et al. 2009).

The characteristics of NOM were also found to affect DBPs formation. Hydrophobic NOM, content phenolic acidity, and ultraviolet absorbance showed higher halogenated organics formation potential (Chen et al. 2008; Wang et al. 2013). It is considered to be the more important source of DBPs precursors than hydrophilic. However, hydrophilic compounds are also found to contribute in the formation of DBPs, especially in low humic waters (Hua and Reckhow 2007; Han et al. 2015).

A number of characterization techniques have been employed to obtain a better understanding of the types of NOM present in the source water and their removal or transformation through the water treatment process train (Tran et al. 2015; Lai et al. 2015). High-performance size exclusion chromatography (HPSEC), especially with organic carbon detector (OCD), has proved to be an attractive option for NOM characterization, due to its ease of operation, its ability to detect any type of organic carbon bonded species, and also its simplicity of sample preparation and requirement for minimal sample volume (Lai et al. 2015; Hidayah et al. 2016).

In this study, HPSEC was used to characterize the NOM in the source water and the treated water from coagulation under various dosage of alum. Peak-fitting technique was applied to resolve the chromatographic peaks of HPSEC and provide quantitative information on NOM fractions removed by coagulation. Further, NOM fractions' removal, trihalomethanes formation potential (THMFP), and haloacetic acid formation potential (HAAFP) reduction, and NPDOC removal were also explored.

\section{Materials and methods}

\section{Source water}

The source water used in this study was collected from the effluent of the slow sand filters in drinking water treatment plant in Kinmen island, Taiwan. The raw water of the plant was drawn from an eutrophic lake. The treatment train before slow sand filtration included coagulation, dissolved air floatation, and rapid sand filtration.

\section{Coagulation}

Alum $\left(\mathrm{Al}_{2}\left(\mathrm{SO}_{4}\right)_{3} \cdot 18 \mathrm{H}_{2} \mathrm{O}\right.$, Merck, Germany) was used as coagulant with various dosage 4,8 , and $16 \mathrm{mg} / \mathrm{L}$ as $\mathrm{Al}$ $(0.15 ; 0.30 ; 0.59 \mathrm{mmol} / \mathrm{L}$ as $\mathrm{Al})$. A variable speed, sixpaddle gang stirrer (Jar test apparatus, Phipps and Bird, Richmond, Virginia, USA) was used. The filtered source water samples $(1 \mathrm{~L})$ were placed on the gang stirrer with three samples tested at a time and the coagulant was added while stirring at $100 \mathrm{rpm}$. After $3 \mathrm{~min}$ of rapid mixing at $100 \mathrm{rpm}$, the speed was reduced to $35 \mathrm{rpm}$ for $15 \mathrm{~min}$, then allowed to settle for $15 \mathrm{~min}$. The supernatants were collected and filtered through $0.45 \mu \mathrm{m}$ filter (cellulose acetate, Advantec, Japan) before further analysis.

\section{Water quality analysis}

The water samples, including source water and the supernatants, were analysed for general physicochemical characteristics, such as non-purgeable dissolved organic carbon (NPDOC), ultraviolet absorbance at $254 \mathrm{~nm}\left(\mathrm{UV}_{254}\right)$, $\mathrm{pH}$, and alkalinity, based on procedures from Standard Methods (APHA et al. 2012). NPDOC was measured by the combustion-infrared method using a total organic carbon analyzer (Model TOC-500, Shimadzu, Kyoto, Japan). $\mathrm{UV}_{254}$ was measured using a UV/Vis spectrophotometer (Model U-2001, Hitachi, Japan) with a 1-cm quartz cell.

\section{HPSEC-OCD and UVD analysis}

To investigate the composition of dissolved organic matter as a function of apparent molecular weight (AMW), high-performance liquid chromatography (HPLC, LC-20 ATV, Shimadzu, Japan)-size exclusion chromatography (SEC) was conducted with sequential on-line detectors UVD-OCD. The chromatographic column $(20$ (I.D.) $\times 200$ (L) mm TSK HW-50S, Toso, Japan) was a weak cation exchange resin (Toyopearl HW-50S, $30 \mu \mathrm{m}$ ) based on polymethacrylate basis. The eluent system consisted of phosphate buffer $\left(2.4 \mathrm{mM} \mathrm{NaH}_{2} \mathrm{PO}_{4}+1.6 \mathrm{mM} \mathrm{Na}_{2} \mathrm{HPO}_{4}\right.$; pH 6.8), containing sodium sulphate $(25 \mathrm{mM})$, to achieve an ionic strength of $100 \mathrm{mM}$. The eluent flow rate was $0.5 \mathrm{~mL} / \mathrm{min}$, and the sample volume is $2 \mathrm{~mL}$. The system was calibrated with polyethylene glycol (PEG) standards ranging from 300 to $110,000 \mathrm{~g} / \mathrm{mol}$, as PEG was reported to have low undesirable interactions with Toyopearl HW resin within the column (Her et al. 2002). A semilog calibration curve (Fig. 1) was used to calculate the AMWs. Prior to chromatographic separation, the samples were made particle-free by passing through a $0.45-\mu \mathrm{m}$ filter (cellulose acetate, Advantec, Japan).

Chromatograms were analysed using peak-fitting technique to resolve the overlapping peaks and to determine the area under each peak. PeakFit (Version 4.12, Systat Software Inc., CA, USA), a commercially available software package, was used for this analysis. The procedure was adapted from the method described by Lai et al. (2015). 


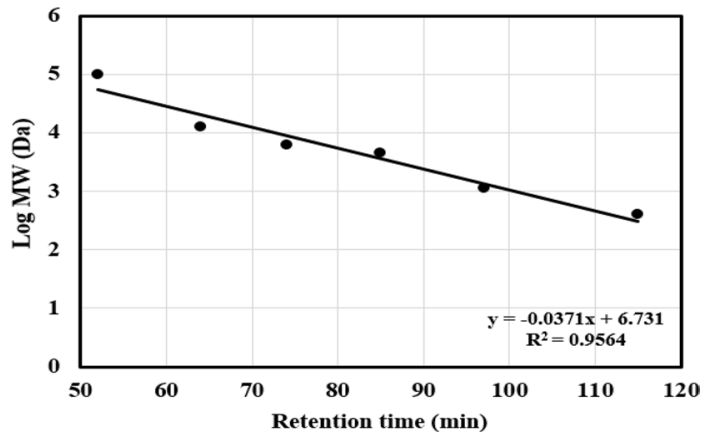

Fig. 1 PEG calibration curve for molecular weight distribution

\section{Disinfection by-products formation potential (DBPFP) analysis}

For the DBP precursor analysis, the $\mathrm{pH}$ value of water samples was kept at $7.0 \pm 0.2$ by first adding $\mathrm{H}_{2} \mathrm{SO}_{4}$ or $\mathrm{NaOH}$ (Merck, Germany) solution, and followed by adding adequate amount of phosphate buffer solution $(0.8 \mathrm{M}$, Merck, Germany). Then, an adequate amount of sodium hypochlorite solution ( $30 \mathrm{mg} \mathrm{Cl} / \mathrm{mL}$, Merck, Germany) was injected into the samples to ensure that at least $1 \mathrm{mg} / \mathrm{L}$ free residual chlorine existed at the end of a 7-day $\left(25^{\circ} \mathrm{C}\right)$ incubation period. Residual chlorine was measured by the DPD ferrous method (APHA et al. 2012). The samples were then dechlorinated by adding sodium thiosulfate solution (0.04 M, Merck, Germany).

Four species of trihalomethanes, namely chloroform, dichlorobromomethane, dibromochloromethane, and bromoform, were measured by the purge and trap packedcolumn gas chromatographic method using a gas chromatograph (Model 3400 GC, Varian, USA) equipped with a purge and trap module (Model LCS-2000, Tekmar USA) and an electron capture detector. The measurement of nine species of haloacetic acids, namely monochloroacetic acid, monobromoacetic acid, dichloroacetic acid, dibromoacetic acid, trichloroacetic acid, tribromoacetic acid, bromochloroacetic acid, dichlorobromoacetic acid, and dibromochloroacetic acid, basically involved liquid-liquid extraction with methyl tertiary butyl ether (MTBE) and esterification with diazomethane prior to GC-ECD analysis.

\section{Results and discussion}

\section{Characteristics of source water}

The general water quality of the source water, which was the effluent from slow sand filter, is shown in Table 1. It can be noticed that source water has neutral $\mathrm{pH}$ and low alkalinity. The NPDOC value indicates that the source water has high
Table 1 Characteristics of source water prior to coagulation

\begin{tabular}{ll}
\hline Water quality & Concentration \\
\hline $\mathrm{pH}$ & 7.2 \\
Alkalinity $\left(\mathrm{mg} / \mathrm{L}\right.$ as $\left.\mathrm{CaCO}_{3}\right)$ & 85 \\
$\mathrm{NPDOC}(\mathrm{mg} / \mathrm{L})$ & 6.8 \\
$\mathrm{UV}_{254}\left(\mathrm{~cm}^{-1}\right)$ & 0.070 \\
$\mathrm{SUVA}(\mathrm{L} / \mathrm{mg}-\mathrm{m})$ & 1.00 \\
\hline
\end{tabular}

dissolved organic content. Further, the SUVA value indicates that the dissolved organics is rich in hydrophilic compounds. As certain types of NOM adsorb $\mathrm{UV}_{254}$ light per unit concentration of DOC to a great degree than other types, SUVA is an indicator of NOM composition in water. It has been reported that water samples with SUVA values higher than 4 indicate that NOM is mainly composed of aquatic humic matter, while water samples with SUVA values lower than 2 contain mainly non-humic matter, which generally is more hydrophilic (Silanpää et al. 2015a).

Figure 2 shows the variations in the dissolved organic content with AMW of the source water, obtained using by HPSEC chromatography equipped with OCD, as well as the results from peak-fitting. The higher peak heights reflect higher concentration of dissolved organic compound. The major dissolved organic groups of the source water based on AMW include four peaks, namely Peaks A, B, C, and D, with AMW of about 50,000, 1650, 1300, and $630 \mathrm{Da}$, respectively.

Figure 3 shows the overlapping figures of the HPSECOCD and UVD chromatograms. It indicates that Peak A of HPSEC-OCD has no corresponding peak in UVD chromatograms, while the Peaks B, C, and D have. As OCD can detect all NOM containing carbon, while only NOM with conjugated or aromatic organic constituents absorb ultraviolet light, Peak A is probably contributed by biopolymers, such as polysaccharide or protein, which are hydrophilic. The other peaks can be associated with humic substances, HS (Peak B), building blocks (Peak C) which represent HS-like

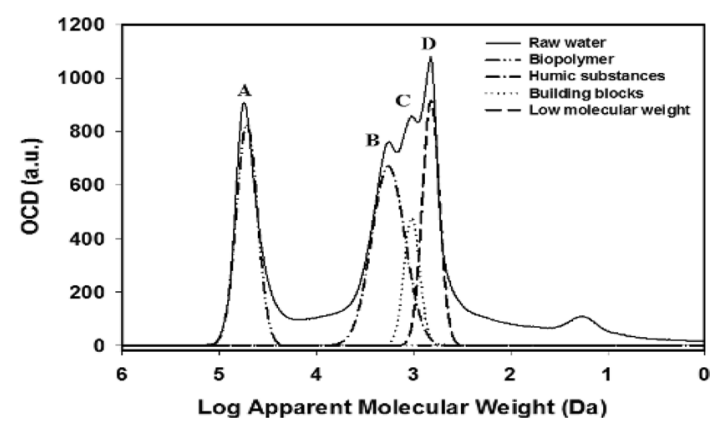

Fig. 2 Distribution molecular weight of organic fractions as detected by HPSEC-OCD in slow sand filter effluent 


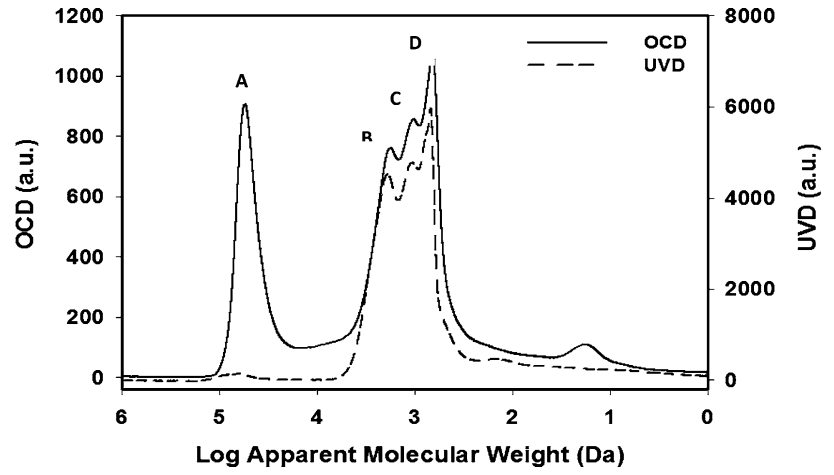

Fig. 3 HPSEC-OCD and -UVD of slow sand filter effluent

Table 2 The peak area and percentage distribution of the resolved peaks of the HPSEC-OCD chromatograms of source water with peakfitting

\begin{tabular}{lll}
\hline Organic fractions & Area $(\mathrm{AU})$ & Percentage $(\%)$ \\
\hline Peak A & 309.7 & 33.6 \\
Peak B & 243.4 & 26.4 \\
Peak C & 181.9 & 19.7 \\
Peak D & 186.9 & 20.3 \\
Total & 921.9 & 100 \\
\hline
\end{tabular}

$A U$ arbitrary unit

materials of lower molecular weight, and low molecular weight acids (Peak D) (Huber et al. 2011; Lai et al. 2015). The peak area and percentage distribution of the resolved peaks of the HPSEC-OCD chromatogram in source water by peak-fitting are shown in Table 2 . It can be noticed that the percentage area contributed by Peak $\mathrm{A}$ is higher than those of other peaks. This means the source water contains quite large amount of hydrophilic organic, which is also reflected in the low SUVA value of the source water.

The raw water of the treatment plant is from an eutrophic lake, and the water samples for this study were collected in March, which was in the middle of dry season. Therefore, the hydrophilic organic is probably due to the biological activities in the lake itself, as seen in the production of extracellular polymeric substances (EPS), which include polysaccharide, protein, and so on (Sillanpää et al. 2015b). However, the area of Peak B, C, and D, which contain UVabsorption hydrophobic organics, contributed significantly to total area of the chromatograms. Therefore, their effect on the water treatment, such as DBPs formation, could not be ignored. As the source water contains high concentration of organic matter, and coagulation is the most efficient unit for NOM removal in conventional water treatment process, it was employed for investigating the characteristic of organic fractions related to DBPs formation.

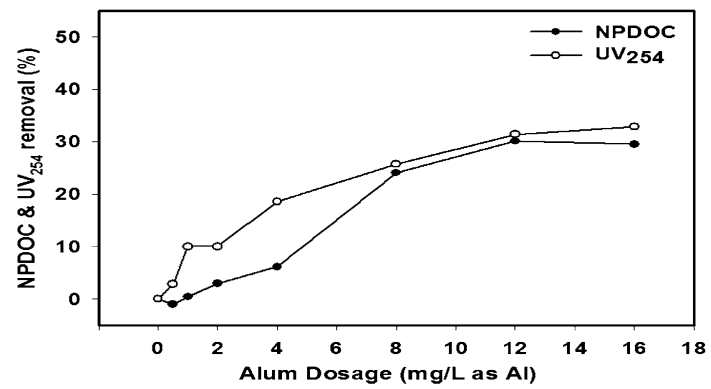

Fig. 4 Organic removal under various alum dosage

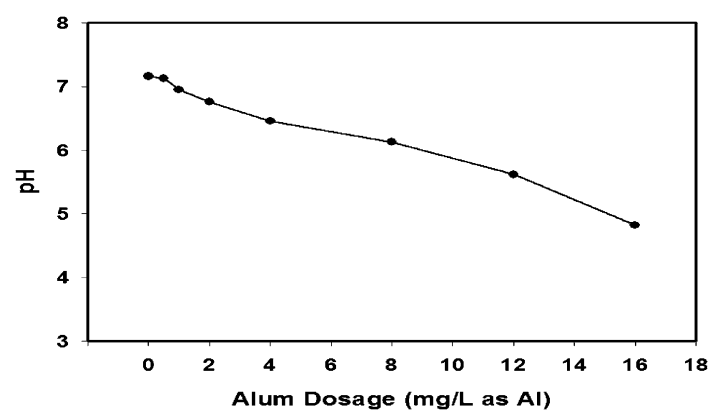

Fig. 5 pH values of supernatants under various alum dosage

\section{NOM fractions removal by coagulation}

The percentage removal of NPDOC and $\mathrm{UV}_{254}$ under various dosage is shown in Fig. 4. First, it reveals that the removal of both parameters increased with increasing coagulant dosage. However, it levelled off when alum dosage was higher than $12 \mathrm{mg} / \mathrm{L}$ as $\mathrm{Al}(0.45 \mathrm{mmol} / \mathrm{L}$ as Al). The highest NPDOC removal is about $30 \%$. This is consistent with that reported in the literature, which indicated that the DOC removal by coagulation was less than $20-40 \%$, when the SUVA value of the source water was less than 2 (Silanpää and Matilainen 2015). This is because of low SUVA value indicates the NOM in source water contains high proportion of hydrophilic organics, which are more difficult to be removed by coagulation. Figure 4 also shows the percentage of $\mathrm{UV}_{254}$ removal is higher than that of NPDOC. This can be explained by the fact that NOM molecules with aromatic structure and conjugated $\mathrm{C}=\mathrm{C}$ double bond, i.e. the humic fractions, absorb more UV light per unit concentration of DOC than the general NOM molecules (Silanpää et al. 2015a).

Figure 5 shows the $\mathrm{pH}$ values of supernatants from coagulation drop consistently with increasing alum dosage. This is due to the reaction between alum and alkalinity; more alkalinity was reduced by increasing coagulant dose with a consequent reduction in $\mathrm{pH}$. 
Figure 6 shows the HPSEC-OCD and UVD chromatograms of the source water and supernatants under alum doses 4,8 , and $16 \mathrm{mg} / \mathrm{L}$ as $\mathrm{Al}(0.16 ; 0.30$; and $0.59 \mathrm{mmol} / \mathrm{L}$ as $\mathrm{Al}$ ). Table 3 lists the area of Peak A-D (from peak-fitting) of the source water and the supernatants after coagulation, and the percentage reduction in the area of each peak, as compared to that of the source water. First, it can be seen that the heights of all peaks of the HPSEC chromatograms decreased with increasing coagulant dosage, also shown in Table 3. Table 3 also shows that the area of individual Peak A to $D$ and the sum of the area of all peaks decreased with increasing alum dosage. This is consistent with the increase in NPDOC removal with increasing alum dosage, as shown in Fig. 4. According to Figs. 4 and 6, significant removal of $\mathrm{UV}_{254}$ than NPDOC under alum doses less than $8 \mathrm{mg} / \mathrm{L}$ indicated removal of humic substance fraction as represented
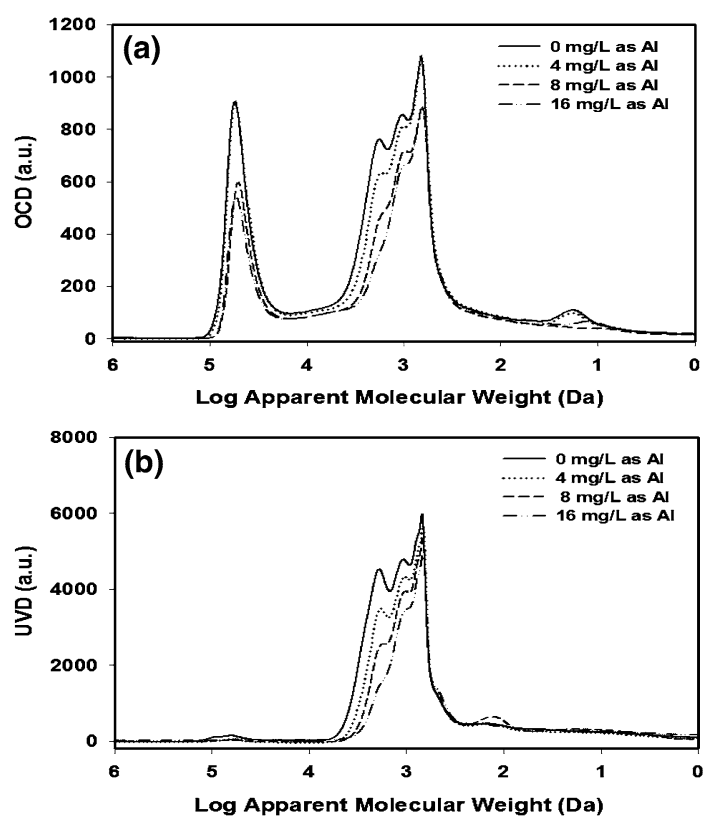

Fig. 6 a HPSEC-OCD and b HPSEC-UVD chromatograms of coagulated water under various alum dosages by Peaks B, C, and D removal. Further, NPDOC removal became close to $\mathrm{UV}_{254}$ removal under alum doses higher than $8 \mathrm{mg} / \mathrm{L}$. It is probably related to the removal of biopolymer fractions, which is represented by Peak A.

Second, Table 3 also reveals that Peak A has almost similar reduction as that of Peak B, while Peaks C and D have much lower removal. The decrease in Peak A of coagulated water corresponded well to the reduction of larger molecular weight by charge neutralization and bridge action, while the remaining compound presented a low conjugated bond of Peak A that could not be removed through those mechanism (Han et al. 2015). According to Fig. 4, Peaks B, C, and D of OCD have corresponding peak in the UVD chromatograms. Peak B, which represents humic substances, also Peaks C and $\mathrm{D}$, which represent lower molecular weight, are featuring molecules with aromatic structure and conjugated $\mathrm{C}=\mathrm{C}$ double bonds, contain NOM which are more hydrophobic than Peak A. The percentage reduction of the sum of the areas of Peaks B, C, and D is higher than the reduction of Peak A. It has been well established in the literature that hydrophobic are more amenable to removal by coagulation than hydrophilic, since hydrophobic NOM has been noted to carry high levels of negative charge due to the presence of ionized groups such as carboxylic (Zhu et al. 2014; Sillanpää and Matilainen 2015; Hidayah et al. 2016).

Table 4 shows the NPDOC, THMFP, and HAAFP of the source water and supernatants from coagulation under alum dosage of 4 and $8 \mathrm{mg} / \mathrm{L}$ (as $\mathrm{Al}$ ). It clearly shows that

Table 4 The NPDOC and THMFP of the source water and treated water after alum coagulation

\begin{tabular}{lccr}
\hline Organic parameter & Source water & \multicolumn{2}{l}{$\begin{array}{l}\text { Treated water (alum dosage, } \\
\mathrm{mg} / \mathrm{L} \text { as Al or mmol/L as Al) }\end{array}$} \\
\cline { 3 - 4 } & & $4(0.15)$ & \multicolumn{1}{c}{$8(0.30)$} \\
\hline NPDOC $(\mathrm{mg} / \mathrm{L})$ & 6.8 & $6.4\left(5.9^{\mathrm{a}}\right)$ & $5.2\left(23.5^{\mathrm{a}}\right)$ \\
THMFP $(\mu \mathrm{g} / \mathrm{L})$ & 313.6 & $245.7\left(21.7^{\mathrm{a}}\right)$ & $213.6\left(31.9^{\mathrm{a}}\right)$ \\
HAAFP $(\mu \mathrm{g} / \mathrm{L})$ & 299.6 & $253.1\left(15.5^{\mathrm{a}}\right)$ & $223.5\left(25.4^{\mathrm{a}}\right)$ \\
\hline
\end{tabular}

${ }^{\text {a }}$ Percentage reduction as compared to that of source water
Table 3 The organic fractions' removal by coagulation under various alum dosage using HPSEC-OCD chromatograms combined with peak-fitting

\begin{tabular}{|c|c|c|c|c|}
\hline \multirow[t]{2}{*}{ Organic fractions } & \multirow[t]{2}{*}{ Source water } & \multicolumn{3}{|c|}{ Treated water (alum dosage, $\mathrm{mg} / \mathrm{L}$ as $\mathrm{Al}$ or $\mathrm{mmol} / \mathrm{L}$ as $\mathrm{Al}$ ) } \\
\hline & & $4(0.15)$ & $8(0.30)$ & $16(0.59)$ \\
\hline Peak A & 309.7 & $297.7\left(1.3^{\mathrm{b}}\right)$ & $197.7\left(12.1^{b}\right)$ & $185.6\left(13.5^{\mathrm{b}}\right)$ \\
\hline Peak B & 243.4 & $214.8\left(3.1^{\mathrm{b}}\right)$ & $152.7\left(9.8^{\mathrm{b}}\right)$ & $128.0\left(12.5^{\mathrm{b}}\right)$ \\
\hline Peak C & 181.9 & $173.6\left(0.9^{\mathrm{b}}\right)$ & $151.5\left(3.3^{\mathrm{b}}\right)$ & $134.1\left(5.2^{\mathrm{b}}\right)$ \\
\hline Peak D & 186.9 & $181.1\left(0.6^{\mathrm{b}}\right)$ & $158.7\left(3.1^{\mathrm{b}}\right)$ & $159.7\left(3.0^{\mathrm{b}}\right)$ \\
\hline Total & 921.9 & $867.2\left(5.9^{\mathrm{a}}\right)$ & $660.6\left(28.3^{\mathrm{a}}\right)$ & $607.4\left(34.1^{\mathrm{a}}\right)$ \\
\hline
\end{tabular}

${ }^{\text {a }}$ Percentage reduction in total peak area between source water and treated water

${ }^{\mathrm{b}}$ Percentage reduction $\quad$ in each peak $\frac{(\text { Area of specific peak })_{\text {raw }}-(\text { Area of specific peak })_{\text {rreated }}}{(\text { Total area })_{\text {raw }}-(\text { Total area })_{\text {rreated }}} \times \%$ removal of total peak area

peak $\quad=$


the reduction in THMFP is higher than that of NPDOC and HAAFP. It has been well established in the literature that hydrophobic NOM, which generally has higher aromatic content, phenolic acidity, and ultraviolet absorbance, shows higher halogenated organics formation potential (Chen et al. 2008; Wang et al. 2013). This means the subgroup of NOM represented by THMFP should have higher SUVA value and hydrophobicity than that of the general natural organics. As coagulation also tends to have higher removal of hydrophobic NOM than hydrophilic fractions, the THMFP reduction by coagulation is higher than HAAFP and NPDOC. This is also consistent with the results show in Table 3, which indicates that hydrophobic fractions, which is mainly represented by Peaks B reduction, has the largest reduction than hydrophilic fractions by coagulation with alum. In addition, it seems that THMFP formation could be inhibited by lower $\mathrm{pH}$. Figure 5 shows that $\mathrm{pH}$ is less than 6 under alum dosage of 8 and $16 \mathrm{mg} / \mathrm{L}$. It indicated that decreasing of THMFP depends on the decreasing of $\mathrm{pH}$ value, instead of organic removal (Liang and Singer 2003).

\section{Conclusions}

Source water from effluent of slow sand filter contains more aromatic humic substances as detected by HPSEC-OCD and HPSEC-UVD, in addition to aliphatic biopolymers. This study reveals that among all NOM fractions, alum coagulation mainly removed hydrophobic aromatic, which is mainly humic substance. The reduction in THMFP was found to be higher than that of NPDOC under specific alum dosage, and the former was also found to be proportional to the corresponding reduction in the area of hydrophobic aromatic fraction, mostly humic subtances, as obtained from HPSEC chromatogram with peak-fitting.

Acknowledgements The financial support provided to this study by the Ministry of Science and Technology, Taiwan (Contract no. 101-2221-E-006-156-MY3) is greatly appreciated.

\section{Compliance with ethical standards}

Conflict of interest The authors declare no conflicts of interest.

Open Access This article is distributed under the terms of the Creative Commons Attribution 4.0 International License (http://creativecomm ons.org/licenses/by/4.0/), which permits unrestricted use, distribution, and reproduction in any medium, provided you give appropriate credit to the original author(s) and the source, provide a link to the Creative Commons license, and indicate if changes were made.

\section{References}

APHA, AWWA, WEF (2012) Standard methods for the examination of water and wastewater, 21 st edn. APHA, Washington, DC

Aslam Z, Chow CWK, Murshed F, van Leeuwen J, Drikas M, Wang D (2013) Variation in character and treatability of organics in river water: an assessment by HPAC and alum coagulation. Sep Purif Technol 120:162-171

Chen C, Zhang XJ, Zhu LX, Liu J, He WJ (2008) Disinfection byproducts and their precursors in a water treatment plant in North China: seasonal changes and fraction analysis. Sci Tot Environ 397(1):140-147

Chow CW, van Leeuwen JA, Fabris R, Drikas M (2009) Optimised coagulation using aluminium sulfate for the removal of dissolved organic carbon. Desalination 245(1):120-134

Han Q, Yan H, Zhang F, Xue N, Wang Y, Chu Y, Gao B (2015) Trihalomethanes (THMs) precursor fractions removal by coagulation and adsorption for bio-treated municipal wastewater: Molecular weight, hydrophobicity/hydrophily and fluorescence. J Hazard Mater 297:119-126

Her N, Amy G, Foss D, Cho J, Yoon Y, Kosenka P (2002) Optimization of method for detecting and characterizing NOM by HPLC-size exclusion chromatography with UV and on-line DOC detection. Env Sci Tech 36:1069-1076

Hidayah EN, Chou YC, Yeh HH (2016) Using HPSEC to identify NOM fraction removal and the correlation with disinfection byproduct precursors. Wat Sci Technol Wat Supply 16(2):305-313

Hidayah EN, Chou YC, Yeh HH (2017) Comparison between HPSECOCD and F-EEMs for assessing DBPs formation in water. J Environ Sci Health Part A 52(4):391-402

Hua G, Reckhow DA (2007) Characterization of disinfection byproduct precursors based on hydrophobicity and molecular size. Environ Sci Technol 41(9):3309-3315

Huber SA, Balz A, Abert M, Pronk W (2011) Characterisation of aquatic humic and non-humic matter with size-exclusion chromatography-organic carbon detection-organic nitrogen detection (LC-OCD-OND). Wat Res 45(2):879-885

Lai CH, Chou YC, Yeh HH (2015) Assessing the interaction effects of coagulation pretreatment and membrane material on UF fouling control using HPSEC combined with peak-fitting. J Membrane Sci 474:207-214

Liang L, Singer PC (2003) Factors influencing the formation and relative distribution of haloacetic acids and trihalomethanes in drinking water. Environ Sci Tech 37(13):2920-2928

Roccaro P, Chang HS, Vagliasindi FG, Korshin GV (2008) Differential absorbance study of effects of temperature on chlorine consumption and formation of disinfection by-products in chlorinated water. Wat Res 42(8):1879-1888

Sharp EL, Jarvis P, Parsons SA, Jefferson B (2006) Impact of fractional character on the coagulation of NOM. Coll Surf Physicochem Eng Aspects 286(1-3):104-111

Sillanpää M, Matilainen A (2015) NOM removal by coagulation. In: Silaanpää M (ed) Natural organic matter in water: characterization and treatment method. Butterworth-Heinemann, Oxford, pp 55-80

Sillanpää M, Matilainen A, Lahtinen T (2015a) Characterization of NOM. In: Silaanpää M (ed) Natural organic matter in water: characterization and treatment method. Butterworth-Heinemann, Oxford, pp 17-53

Sillanpää M, Metsämuuronen S, Mänttäri M (2015b) Membranes. In: Silaanpää M (ed) Natural organic matter in water: characterization and treatment method. Butterworth-Heinemann, Oxford, pp $113-157$

Tran NH, Ngo HH, Urase T, Gin KYH (2015) A critical review on characterization strategies of organic matter for wastewater and water treatment processes. Biores Technol 193:523-533 
Wang DS, Zhao YM, Yan MQ, Chow CWK (2013) Removal of DBP precursors in micro-polluted source waters: A comparative study on the enhanced coagulation behaviour. Sep Purif Technol 118:271-278

Zhu G, Yin J, Zhang P, Wang X, Fan G, Hua B, Ren B, Zheng H, Deng B (2014) DOM removal by flocculation process: fluorescence excitation-emission matrix spectroscopy (EEMs) characterization. Desalination 346:38-45
Publisher's Note Springer Nature remains neutral with regard to jurisdictional claims in published maps and institutional affiliations. 